\title{
RICHARD SWINBURNE E A POSSIBILIDADE DE FUNDAMENTAÇÃO RACIONAL DA CRENÇA EM DEUS
}

\author{
João Víctor Oliveira Gomes \\ Graduando em Filosofia pela Universidade de Brasília - UnB
}

\begin{abstract}
RESUMO
Este artigo tem como objetivo responder até que ponto a proposta de justificação teísta apresentada por Richard Swinburne responde às críticas de Hume e Kant quanto à possibilidade de fundamentação racional da crença na existência de Deus. Para isso, a seguinte metodologia será adotada: em primeiro lugar, serão apresentadas as objeções dos dois autores citados; em seguida, terá lugar uma exposição das respostas de Swinburne, com ênfase em aspectos específicos da sua versão do argumento teleológico e no princípio da simplicidade adotado como critério de escolha entre hipóteses conflitantes. Na sequência, serão expostas e discutidas algumas das críticas contemporâneas ao trabalho de Swinburne. Por fim, com base na discussão realizada, será dada uma resposta à questão inicial do artigo.
\end{abstract}

Palavras-chave: Immanuel Kant. David Hume. Teologia natural. Justificação teísta. Richard Swinburne.

\begin{abstract}
This article aims to answer the extent to which the proposal of theistic justification presented by Richard Swinburne answers criticisms by Hume and Kant on the possibility of racional foundation of belief in the existence of God. For this, the following methodology is adopted: firstly, we present the objections of the two authors mentioned, then there will be an exhibition of Swinburne's responses, with emphasis on specific aspects of his version of the teleological argument and the principle of simplicity adopted as a criterion for choosing between conflicting hypotheses. Following, will be presented and discussed some contemporary criticism on Swinburne's work. Finally, based on the discussions held, will be given an answer to the initial question of the article.
\end{abstract}

Key-words: Immanuel Kant; David Hume; Natural Theology; Theistic Justification; Richard Swinburne.

\section{Introdução}

A tarefa de fundamentar racionalmente a crença em uma divindade sobrenatural, inteligente e intencional tem tido grande importância desde o começo da filosofia, remontando ao pensamento grego e tendo adquirido destaque ainda maior na filosofia medieval. Dentro dessa tentativa de fundamentação, temos a teologia natural, de onde surgiram os principais argumentos a favor da existência de Deus ${ }^{1}$.

1 Para os fins desta discussão, adotaremos o conceito do deus teísta oferecido por Richard Swinburne, principal autor a ser discutido neste texto. Segundo ele, Deus é uma pessoa incorpórea (um espírito) que é eterno, perfeitamente livre, onipotente, onisciente, sumamente bom e criador de todas as coisas (SWINBURNE 2004). 
No século XVIII, duas obras obtiveram enorme influência no crescente descrédito desse tipo de investigação em filosofia: os Diálogos da Religião Natural, de David Hume, e a Crítica da Razão Pura, de Immanuel Kant. Hume, por meio de vários argumentos, critica a possibilidade de investigação racional nessa área, direcionando seus ataques aos principais argumentos de teologia natural. Kant, por outro lado, defende que todos os argumentos a favor da existência de Deus têm como fundamento último o argumento ontológico. Como este não é bem-sucedido e Deus está fora do campo da experiência possível, Kant defende, concordando com Hume, a impossibilidade de conhecimento dessa questão.

A filosofia do século XIX parece ter tomado as teses de Hume e Kant como resultados estabelecidos. Desse modo, as principais críticas ateias desse período, feitas por autores como Feuerbach, Nietzsche e Marx, não apresentam argumentos contra a existência de Deus, voltando-se para outros aspectos da atividade e crença religiosas.

Após a derrocada do positivismo lógico e de sua tentativa de declarar sem sentido toda linguagem que não fizesse referência a objetos e estados de coisas diretamente observáveis, a teologia natural foi, aos poucos, ressurgindo no cenário filosófico contemporâneo. Nesse contexto, tem grande importância a proposta do filósofo britânico Richard Swinburne de reformular alguns dos argumentos mais conhecidos a favor da existência de Deus em termos do raciocínio indutivo probabilístico bayesiano. O presente artigo tem como objetivo analisar até que ponto o trabalho de Swinburne responde as objeções de Hume e Kant, para os quais a questão da existência de Deus estaria além dos limites da razão humana.

\section{Os Diálogos de Hume}

Nos Diálogos, Hume monta uma conversa entre três amigos, Fílon, Cleantes e Demea, tendo como assunto a existência de Deus. Nessa conversa, o debate acerca do argumento do desígnio tem grande destaque, ocupando mais da metade do livro. No entanto, também são discutidos o argumento da causa primeira (uma das versões do argumento cosmológico), o problema do mal e a relação entre religião e moral. Tendo em vista o objetivo deste artigo, não falaremos do que é dito acerca do argumento cosmológico, da relação entre religião e moral e sobre o problema do mal, atendo-nos ao argumento do desígnio ${ }^{2}$.

2 As críticas mais contundentes de Hume versam sobre o argumento do desígnio. Seu tratamento dos outros três temas não obteve grande atenção, principalmente, cremos, pelos seguintes motivos: o argumento cosmológico criticado por ele não é dos mais sofisticados; e, ao falar do problema do mal, Hume não traz nenhuma contribuição ao tema, apenas invocando o chamado paradoxo de Epicuro e enumerando uma série de males do mundo. Quanto à relação entre religião e moral, foge ao propósito deste artigo abordar tal tema. 


\title{
2.1 O argumento do desígnio
}

Este argumento é apresentado nos Diálogos da seguinte forma:

\begin{abstract}
"Olhai o mundo ao redor. Contemplai-o no todo e em cada uma das suas partes. Verificareis que é apenas uma grande máquina, subdividida num número infinito de máquinas menores, que admitem novas subdivisões num grau que ultrapassa os sentidos e as faculdades humanas que podem investigar e explicar. Todas estas diversas máquinas e, mesmo as suas partes mais pequenas, estão ajustadas umas às outras com uma precisão que fascina todos aqueles que já as contemplaram. Por toda a natureza, a extraordinária adaptação dos meios aos fins assemelha-se exactamente, embora as exceda em muito, às produções da invenção, desígnio, pensamento, sabedoria e inteligência humanas. Por consequência, uma vez que os efeitos são semelhantes, somos levados a inferir, por todas as regras da analogia, que as causas também são semelhantes e que o Autor da natureza é um pouco similar à mente humana, embora dotado de faculdades muito mais vastas, proporcionais à grandeza da obra que executou.” (HUME, 1779, pp. 28-29).
\end{abstract}

Tendo exposto o argumento, vejamos, abaixo, as principais críticas de Hume a ele.

\subsubsection{A fraqueza da analogia}

Uma analogia é forte na medida em que são semelhantes os objetos comparados. Se observamos uma casa, ou uma máquina, inferimos daí que foi projetada por uma mente inteligente e intencional, pois é este o tipo de efeito (a casa ou máquina) que sabemos advir daquele tipo de causa (inteligência intencional). Mas a semelhança do universo com uma casa ou com uma máquina não é forte o bastante para que se estabeleça a existência de desígnio nele. Podemos obter da casa, que observamos empiricamente, um conhecimento amplo de suas propriedades, mas não temos o mesmo conhecimento do universo. Poderíamos, por exemplo, supor que a matéria tenha em si a fonte ou origem da ordem que se lhe atribui, e que, por uma causa desconhecida (que não seja Deus), os elementos se arranjam da forma admirável como fazem. Isso não seria mais difícil do que a suposição de que, por uma causa igualmente desconhecida, as ideias se arranjam na mente divina.

Além disso, a inferência feita da parte para o todo é desproporcional e ilegítima. Por sabermos uma das causas da natureza (a mente humana) não podemos inferir, daí, que toda a natureza é causada por algo semelhante. A desproporção entre o que sabemos do universo e o próprio universo é tão grande que não estamos autorizados a tal salto indutivo. E mesmo que 
pudéssemos fazer a passagem da parte ao todo, não há razão para escolher algo semelhante ao desígnio humano como causa do universo, pois este é apenas uma das causas existentes, sendo, além disso, uma causa bastante limitada e fraca.

\subsubsection{O término da explicação}

Essa crítica tem como foco a ideia de que o argumento do desígnio não explica a ordem do universo, pois, ao recorrer a uma ordem mental para explicar a ordem material, a questão permanece, já que podemos, também, pedir uma causa para essa ordem mental. Assim, acabaríamos num retorno ad infinitum de causas. Pode-se argumentar que a ordem mental tem causa em si mesma. Mas também é possível supor que a ordem material tenha causa em si mesma. Por que não parar no mundo material? Se passamos deste, incitamos perguntas que nunca serão satisfatoriamente respondidas. Assim, supor que o mundo tenha em si a causa da sua ordenação não é menos aceitável que supor um desígnio para essa ordem.

\subsubsection{A arbitrariedade teológica como consequência do desígnio}

O argumento do desígnio, como apresentado, assemelha Deus ao ser humano através da analogia feita entre inteligência humana e inteligência divina. Isso não permite, em primeiro lugar, que se atribua infinitas propriedades a Deus, pois, se a causa é proporcional ao efeito, e não sabemos se o efeito é infinito, não se pode estabelecer que a causa o seja. Em segundo lugar, também não se pode atribuir perfeição a Deus, pois não sabemos se o mundo é perfeito. Sendo assim, ainda que admitamos que a analogia se sustenta, não há como fundamentar nada além da existência do desígnio.

A partir daí, Hume apresenta uma série de hipóteses alternativas àquela do deus teísta, que seriam, em sua opinião, igualmente possíveis: poderíamos supor que vários deuses tivessem trabalhado em conjunto para produzir o universo, como acontece no caso de seres humanos construindo as casas utilizadas na construção do argumento; poderíamos dizer que a divindade ou divindades teriam traços humanos físicos, e não apenas mentais (chegaríamos, desse modo, a um antropomorfismo completo); poderíamos dizer que o universo é obra de um deus infantil, ou senil, ou até mesmo de uma divindade incompetente, subalterna. Com base no argumento do desígnio, não teríamos base para estabelecer uma teologia com segurança e qualquer deidade sugerida seria apenas uma suposição, entre tantas outras. Todos os sistemas religiosos seriam possíveis e a escolha entre eles seria totalmente arbitrária. De modo bastante 
sucinto: o argumento do desígnio, ainda que se admita sua correção, não permite a determinação da natureza de Deus.

\section{A "Dialética Transcendental" de Kant}

Para Kant, o conceito de Deus é o ideal da razão pura, necessário para a determinação completa de objetos a priori. Por faltarem condições suficientes na experiência para isso, esse conceito é transcendente. Para essa determinação completa ocorrer (ou seja, para se conhecer inteiramente algo), é preciso conhecer todo o possível e, desse modo, determinar a coisa, afirmativa ou negativamente. Deve-se poder analisar todos os predicados possíveis e escolher o que caiba ao objeto em questão. Essa ideia do conjunto de toda a possibilidade existe apenas na razão, é um ideal da razão pura, por ser um conceito determinado a priori. $\mathrm{O}$ fundamento desse ideal é a ideia de um todo na realidade. A ideia da realidade suprema é o único ideal autêntico da razão humana. Esse ideal é conhecido quando se concebe um ser que tenha, em si, a possibilidade de toda a realidade.

Podemos determinar esse ser através do conceito de realidade suprema, e teríamos o conceito de um Ser Supremo único, simples, totalmente suficiente, eterno, em uma palavra, um ser incondicionalmente perfeito. O ideal da razão pura é, assim, objeto de uma teologia transcendental. Entretanto, para ser possível a determinação completa das coisas, só a ideia de Deus é necessária. Atribuir existência de um objeto a que corresponda o ideal da razão pura é exceder o uso dessa ideia transcendental. Para dar esse passo a mais, foram formulados os argumentos a favor da existência de Deus.

Kant limita as provas da existência de Deus a três: o argumento ontológico, o argumento cosmológico e o argumento físico-teológico (que não é outro senão o argumento do desígnio). Ele apresenta críticas a essas três provas, para demonstrar que não é possível provar a existência de Deus nem pela experiência nem pela razão pura.

\subsection{O argumento ontológico}

A crítica de Kant ao argumento ontológico não tem grande relevância para a presente discussão, pois o trabalho de Swinburne é majoritariamente indutivo, descartando o argumento ontológico do rol dos argumentos corretos a favor da existência de Deus. No entanto, convém ressaltar a ideia, proposta por Kant, de que é com o argumento ontológico que se dá a determinação completa do conceito de Deus. Em outras palavras, não se pode tirar 
da experiência os atributos infinitos de Deus: é através da razão pura, operando com simples conceitos, que se procura os predicados que cabem a um ser necessário, ocorrendo a determinação completa desse ser. Isso é feito com base no argumento ontológico.

\subsection{O argumento cosmológico}

A crítica de Kant vai de encontro à pretensão do argumento cosmológico de se diferenciar do ontológico, por fazer uso da experiência (ao constatar a existência de algo para, a partir daí, estabelecer a existência de um Ser necessário). Segundo Kant, esse é um artifício que disfarça o uso do argumento ontológico. Essa prova estabelece como fundamento a experiência, mas esse fundamento empírico só é usado para se elevar à existência de um ser necessário em geral. Nada se pode dizer, com base nisso, dos atributos deste Ser necessário: a razão, então, se afasta da experiência e procede à determinação destes atributos através de simples conceitos. Assim, na prova cosmológica, a constatação empírica da existência de algo serve apenas para levar ao conceito de necessidade absoluta, mas em nada ajuda a encontrar essa necessidade em qualquer coisa determinada. A grande força persuasiva desse argumento está na prova ontológica, que ele traz implicitamente. Por esse motivo, o argumento cosmológico é ainda mais falho do que o ontológico, pois traz este último implícito, apesar de se propor a usar outro caminho em sua prova.

\subsection{O argumento físico-teológico}

Este é, como já dito, o argumento do desígnio, também chamado de argumento teleológico. $\mathrm{O}$ argumento tem, de acordo com Kant, três momentos distintos: primeiro, inferese um autor da ordem e finalidade da natureza; após isso, infere-se uma plenitude absoluta dessa mesma ordem e finalidade, que corresponde a um autor necessário; por fim, ao autor necessário é atribuída a natureza de Deus.

Quanto ao primeiro momento da argumentação, Kant critica a analogia que é feita entre a arte humana e o mundo, repetindo vários pontos do que é dito por Hume: nesse caso, passaríamos do conhecido (as obras humanas e suas causas) para o desconhecido (o universo). Essa passagem é ilegítima. Ainda que se aceite essa analogia, não se pode inferir daí um criador do universo, mas no máximo um arquiteto, que opera com a matéria da qual dispõe. Para concluir que há um criador do universo, seria necessário outro fundamento diferente da analogia com a arte humana, pois essa opera sempre limitada pela matéria de que dispõe para 
criar.

Os dois passos seguintes do argumento não podem ser dados apenas com base na fundamentação empírica que a prova físico-teológica propõe. Para concluir que há uma plenitude absoluta na natureza é preciso conceber o todo da realidade e inferir, daí, que é preciso um autor necessário para o universo e que esse autor é Deus. Mas esses passos só podem ser dados usando conceitos transcendentais. Não encontramos na experiência fundamento para a ideia da realidade suprema, nem para a determinação do conceito do ser supremo, de modo que convenha o estatuto de ser necessário a esse ser. O passo de conceber o todo da realidade e inferir a existência de um ser necessário é característico da prova cosmológica e o passo que determina completamente o conceito de Deus (através de simples conceitos a priori) é dado pelo argumento ontológico. Como o argumento cosmológico também se fundamenta com base no argumento ontológico, este último constitui a única prova possível para a existência de Deus.

No entanto, como visto, Kant defende que o argumento ontológico não se sustenta. Para conferir existência a um objeto, é preciso o uso da experiência ${ }^{3}$. Mas o conceito de Deus transcende o campo da experiência possível. Desse modo, não há prova da existência de Deus nem pode haver, tendo em vista o caráter transcendente do conceito do Ser Supremo.

\section{Richard Swinburne e "A existência de Deus"}

O trabalho de Richard Swinburne é de grande relevância dentro da filosofia analítica da religião. Swinburne se propõe a utilizar o aparato fornecido pelos recentes avanços em teoria da probabilidade, nomeadamente, aqueles provenientes do uso do Teorema de Bayes, para defender a existência de Deus. Convém notar, desse modo, que Swinburne não segue a tradição clássica, que tenta provar a existência de um Ser Supremo. Sua abordagem é, por assim dizer, mais modesta, fazendo uso de argumentos indutivos, cumulativamente, para sustentar que a hipótese teísta é mais provável do que suas alternativas ${ }^{4}$. Por esse motivo, Swinburne não parece preocupado em responder às críticas de Kant, pois estas são

3 Como Hume, Kant pensa que a existência é uma questão de fato, ou seja, a negação de uma proposição existencial não implica contradição. É a experiência que pode nos dar o valor de verdade das proposições existenciais, tarefa impossível para a simples razão pura.

4 Swinburne faz uma distinção entre tipos de argumentos indutivos: eles podem ser argumentos C-indutivos, quando confirmam a hipótese, mas não a tornam mais provável do que sua negação, ou podem ser $\mathrm{P}$ indutivos, quando tornam a hipótese mais provável do que sua negação. Segundo ele, nenhum dos argumentos a favor da existência de Deus é um bom argumento P-indutivo, mas sim C-indutivos. No entanto, a conjunção de todos eles, considerados cumulativamente com base no aparato bayesiano, fornece um bom argumento P-indutivo a favor da existência de Deus. 
majoritariamente direcionadas ao argumento ontológico, que faz uso de um raciocínio puramente dedutivo. No entanto, algumas das críticas de Kant são respondidas indiretamente, como veremos adiante.

Para Swinburne, o método indutivo bayesiano formaliza, com rigor, o raciocínio científico moderno. Segundo ele, a ciência opera indutivamente, propondo hipóteses que expliquem melhor os indícios analisados. Nesse sentido, o objetivo de Swinburne é mostrar que o teísmo é uma hipótese tão aceitável quanto qualquer hipótese científica de respeito.

Há dois passos principais no raciocínio bayesiano: a atribuição de uma probabilidade prévia às hipóteses (sua probabilidade, antes que se considere o indício a ser explicado) e a determinação da probabilidade posterior dessas hipóteses (a probabilidade final delas, considerados os indícios analisados). A atribuição de probabilidades prévias é de grande importância, visto que determinará em grande escala a probabilidade posterior de qualquer hipótese. Segundo Swinburne, a probabilidade prévia de uma teoria depende da sua conformidade com nosso conhecimento de fundo, de sua simplicidade e abrangência.

Conformidade com nosso conhecimento de fundo diz respeito ao modo como a hipótese se encaixa com o que já sabemos acerca do mundo. $\mathrm{O}$ conhecimento de fundo abrange conhecimento tautológico e empírico, sendo que, neste último caso, considera-se apenas as teorias empíricas que façam parte da área de pesquisa analisada ou dos campos vizinhos. Trata-se, assim, de um critério a posteriori. Quanto à abrangência de uma teoria, Swinburne pensa que na medida em que aumenta a abrangência, diminui a probabilidade da teoria. Ou seja, na medida em que aumenta a intenção da teoria de se aplicar a mais objetos e dizer mais sobre eles, ela perde probabilidade. Isso se deve ao fato de que, quanto mais se diz, mais chances se tem de errar (SWINBURNE, 2004, p. 55).

A simplicidade desempenha papel fundamental na proposta de Swinburne. Segundo ele, quanto mais simples uma teoria, mais provável ela é; trata-se do princípio da simplicidade. Nas suas palavras:

"Quanto mais simples a teoria, mais provável ela é. A simplicidade de uma teoria, no meu ponto de vista, é uma questão de postular poucas (e logicamente independentes) entidades, poucas propriedades de entidades, poucos tipos de entidades, poucos tipos de propriedades, propriedades mais facilmente observáveis, poucas leis separadas com poucos termos relacionando poucas variáveis, com a formulação mais simples de cada lei sendo matematicamente simples." (SWINBURNE, 2004: p. 53 - tradução livre).

Temos, assim, uma noção de simplicidade majoritariamente matemática e, num 
aspecto específico, ontológica (postular poucas entidades e poucos tipos de entidades). Swinburne vê o juízo sobre a simplicidade de uma teoria como critério objetivo e impessoal de julgar hipóteses. Assim, parece claro que uma noção matemática de simplicidade auxilia enormemente a tarefa de julgar hipóteses, tornando-a mais exata e objetiva.

A simplicidade é, para Swinburne, o critério mais importante para a atribuição de probabilidades prévias. Ele defende que os cientistas, ao julgar hipóteses conflitantes que explicam igualmente bem os indícios analisados, preferem as hipóteses mais simples. Por esse motivo, Swinburne dá grande ênfase à ideia de que o teísmo é a hipótese mais simples para explicar os indícios analisados. Segundo ele, o teísmo, apesar de não ter uma probabilidade prévia alta, é, ainda assim, mais provável, previamente, do que qualquer outra hipótese.

Essa tese se baseia numa concepção de simplicidade segundo a qual é mais simples atribuir, a uma entidade, propriedades em grau infinito do que num grau extremamente alto, mas finito. Segundo Swinburne, os cientistas, por exemplo, preferem atribuir velocidades infinitas ou nulas a atribuir velocidades finitas, mas imensamente grandes. Além disso, é preferível (mais simples) postular apenas uma entidade com poder infinito a postular várias entidades com poderes finitos. Tendo em vista a suposição de que Deus tem suas propriedades em grau infinito (é onipotente, onisciente, perfeitamente bom etc.), segue-se que ele é uma hipótese mais provável do que outro deus que seja muito poderoso, ou tenha uma grande quantidade de conhecimento, mas tenha essas propriedades em grau finito. A hipótese de não atribuir propriedades não é possível, segundo ele, pois, neste caso, não haveria entidade alguma.

Encontramos, neste ponto da discussão, algumas respostas relevantes a Hume. Segundo Swinburne, a hipótese de um único deus é preferível à de vários deuses, pois uma teoria em que se postule apenas uma entidade para explicar os indícios é mais simples do que uma em que se postulem várias entidades. Além disso, uma entidade será mais simples se tiver propriedades em grau infinito do que finito.

Assim, conclui Swinburne, o teísmo é a explicação pessoal mais simples para os indícios analisados. É por esse motivo que Swinburne, ao analisar os argumentos e efetuar o cálculo de probabilidades, considera como hipóteses apenas o teísmo ou o naturalismo, sendo que este não apresenta explicação nenhuma, declarando que os indícios analisados são fatos brutos.

Por fim, Swinburne pensa que podemos determinar totalmente as propriedades de Deus objetivamente. Neste argumento, encontramos uma resposta fundamental a uma crítica que ressoa tanto em Hume quanto em Kant, a questão de saber como determinar a natureza de 
Deus. Hume argumentou que a determinação dessas propriedades, com base no argumento do desígnio, não é possível, enquanto Kant defendeu que a determinação das propriedades de Deus só é possível com base no argumento ontológico. Vejamos, então, o raciocínio de Swinburne.

Segundo ele, as propriedades divinas derivam da onipotência, onisciência e liberdade absoluta de Deus. Deus é incorpóreo, pois, se tivesse um corpo, haveria algo para limitá-lo, o que tornaria sua liberdade imperfeita. Se Deus é onipotente, ele pode controlar todos os estados das coisas em qualquer lugar por meio de ações básicas. Se ele é onisciente, sabe o que está acontecendo em qualquer lugar, sendo, por isso, onipresente. Já que Deus é onipotente, ele poderia impedir que qualquer coisa acontecesse, caso quisesse. Assim, o que quer que aconteça acontece porque ele faz com que aconteça ou permite que outra pessoa o faça: por isso, ele é o criador de todas as coisas. Se aceitarmos que julgamentos morais têm valores de verdade ${ }^{5}$, a bondade perfeita de Deus segue dedutivamente da sua onisciência e da sua liberdade absoluta. Um ser onisciente saberá o valor de verdade de todos os julgamentos morais. Um agente que é perfeitamente livre fará o que ele pensa ser a melhor ação moral, e como Deus é também onisciente, ele fará a melhor ação moral, pois para ele, acreditar em algo é saber algo. O raciocínio de Swinburne é o seguinte: para agir, um agente tem que ter uma intenção. Esse princípio é lógico, não físico. O agente deve agir por um propósito e ver suas ações de algum modo como uma coisa boa. Um agente que não é limitado por nenhuma influência não racional, ou seja, um agente perfeitamente livre tomará sempre o que ele considerar ser a melhor ação acessível a ele. Sendo onisciente, ele saberá qual a melhor ação a se tomar. Sendo onipotente, poderá tomá-la, a menos que ela seja logicamente impossível. Logo, Deus, que é onisciente, onipotente e perfeitamente livre, sempre tomará a melhor ação moral, sendo, por isso, perfeitamente bom.

Swinburne distingue dois tipos de explicação: a científica e a pessoal. A explicação científica é uma explicação em termos de leis da natureza; a pessoal, em termos da ação intencional de um agente pessoal. Para Swinburne, uma explicação pessoal só deve ser proposta quando não houver explicação científica possível para determinado indício. Assim, uma de suas tarefas é defender que, para cada indício analisado, configura-se a inexplicabilidade científica daquele indício. Só desse modo a hipótese de Deus pode ser

5 Não é ponto assentado se há ou não valores de verdade para os juízos morais. No entanto, podemos deixar essa discussão de lado, argumentando que, se Deus existir - algo que se assume, nessa dedução das suas propriedades - há valores de verdade para juízos morais. Essa posição é dominante na tradição teísta, e, considerando que tratamos de uma dedução de propriedades de Deus, pode-se usá-la a favor do argumento de Swinburne. 
introduzida na discussão.

Convém destacar, por ser uma resposta a Hume, a opinião de Swinburne acerca do término adequado de uma explicação científica. Segundo ele, o término da explicação configura-se quando nenhum ganho de poder explanatório compensaria a perda de probabilidade prévia da hipótese. Ou seja, caso a teoria apresentada seja mais complexa do que a teoria que já se tem e, além disso, não traga um ganho de poder explanatório que supere essa complexidade, configura-se o término adequado da explicação.

A explicação naturalista não seria, desse modo, o término adequado da explicação dos indícios, pois ela apenas declara que não há explicação para eles. Considerando que o teísmo é uma hipótese de maior poder explanatório (pois acrescenta algo à explicação dos indícios) e que ele é mais simples do que sua alternativa, o teísmo é, segundo Swinburne, o término mais adequado para a explicação dos indícios.

Com base nessas noções, Swinburne passa a analisar os argumentos, concluindo, ao fim de tudo, que, feito o balanço de probabilidades à luz dos indícios, o teísmo é mais provável do que o naturalismo e que, portanto, Deus existe.

No contexto da presente discussão, tem grande relevância o modo como Swinburne propõe o argumento teleológico. Este argumento tem duas versões no trabalho de Swinburne, cada uma delas partindo de um tipo diferente de ordem do universo. A primeira parte do que ele chama de ordem temporal: são as sucessões regulares dos eventos, codificadas nas leis da natureza. Trata-se do fato de que o universo tem uma ordem que se conforma a leis científicas simples e compreensíveis. A segunda fundamenta-se na ordem espacial do universo, o arranjo intricado e complexo dos corpos humanos e animais, que permitem aos seus portadores adquirir uma enorme quantidade de conhecimento sobre o mundo e realizar seus propósitos nele.

O ponto a ser ressaltado, nestes argumentos, é que eles não são argumentos por analogia, como o são as versões criticadas por Hume e Kant. O próprio Swinburne reconhece essa tentativa de analogia como um erro cometido pelos filósofos do século XVIII e XIX. Assim, seu argumento é construído como um argumento a partir de indícios que provavelmente ocorreriam caso o teísmo fosse verdadeiro, mas não de outro modo. Em cada caso, a ordem que o universo apresenta, diz Swinburne, demanda explicação. O naturalismo pode apenas dizer que não há explicação para essa ordem. No entanto, é improvável que houvesse essa ordem sem explicação. Sendo o teísmo uma hipótese que explica completamente esta ordem e torna provável que ela ocorra - pois Deus, sendo perfeitamente bom, iria querer que houvesse ordem para que os seres humanos pudessem se desenvolver e 
adquirir conhecimento e, para isso, eles precisariam de corpos adequados - a ordem espacial e a ordem temporal constituem dois indícios favoráveis ao teísmo, aumentando sua probabilidade.

São esses os pontos específicos da obra de Swinburne que contém suas principais respostas a Hume e Kant. O princípio da simplicidade é, como se pode notar, a principal fonte de respostas de Swinburne às críticas de Hume e Kant quanto à possibilidade de fundamentação racional da crença na existência de Deus. Em seu uso, encontramos uma resposta à questão da determinação da natureza de Deus (presentes em Hume e Kant) e do término adequado da explicação. Caso a aplicação deste princípio esteja correta, parece claro que Swinburne consegue responder à grande maioria das objeções. Convém, no entanto, antes de dar uma resposta à questão principal do artigo, analisar algumas críticas contemporâneas ao princípio da simplicidade.

\section{Críticas contemporâneas}

O trabalho de Swinburne, como qualquer outra tese filosófica, não está livre de críticas. Neste capítulo, veremos algumas das críticas direcionadas especificamente ao uso de Swinburne do princípio da simplicidade. Estas críticas serão retiradas majoritariamente da tese de doutorado de Agnaldo Portugal, além da obra póstuma de J.J. Mackie, The Miracle of Theism.

\subsection{Mackie e o The Miracle of Theism}

Mackie discute, nessa obra, do mesmo modo que Swinburne, os principais argumentos a favor e contra a existência de Deus. Sua conclusão, no entanto, é oposta à do autor em discussão. Mackie faz diversas críticas aos argumentos teístas, entre eles, à versão de Swinburne do argumento teleológico. Para a presente discussão, merece menção uma crítica de Mackie, transcrita abaixo:

"Ao contrário do que Swinburne diz, a postulação de uma mente divina... em particular se atribuirmos a essa mente o poder de criar um universo do nada e de colocar e manter nele regularidades, através de realizações imediatas de intenções, não é nada simples... A introdução de uma categoria de realização imediata de intenções está em desacordo com o que realmente sabemos sobre nossas próprias ações intencionais, e conforma-se apenas com um entendimento ilusório, simplificado e ingênuo delas. Por essa razão, é 
improvável ao extremo em relação ao nosso conhecimento de fundo." (MACKIE, 1982, p.149)

Assim, para Mackie, a hipótese teísta não é simples, pois não se conforma ao nosso conhecimento de fundo. Não temos nenhuma experiência anterior de uma realização imediata de intenções, ou seja, de um agente que realiza seus propósitos diretamente, sem mediação física e causal, como o teísmo diz que Deus age. Assim, a hipótese teísta não é mais simples do que o naturalismo. É, de fato, muito mais complexa. Por esse motivo, no balanço de probabilidades, Mackie defende que o teísmo é menos provável do que o naturalismo.

Seguindo Mackie, Don Fawkes e Tom Smythe dizem que um ser com propriedades infinitas é um ser extremamente complexo (FAWKES \& SMYTHE, 1996). Por que postular um criador com mais capacidades do que as necessárias para a criação do universo? Por que assumir que ele é imortal, se poderíamos dizer que ele é mortal, e que, após criar o universo, morreu? Uma hipótese que assume mais do que é necessário para explicar um fenômeno não é simples. Se o critério para considerar uma hipótese simples é a economia e parcimônia, uma entidade com um número infinito de qualidades não parece simples de modo algum. Além disso, a mera adição de Deus às causas naturais torna o teísmo menos simples que o rival, dado que ele postula mais entidades para explicar o mesmo fenômeno.

Convém notar, no entanto, que Mackie parece cometer um erro na interpretação da proposta de Swinburne. Este responde a Mackie, em seu artigo Mackie, Induction and God, que simplicidade não tem a ver com o quanto a hipótese é compatível com o nosso conhecimento de fundo (SWINBURNE, 1983, p. 387). De fato, a noção de simplicidade de Swinburne não abrange a conformidade com o conhecimento de fundo. Essa aparente confusão, no entanto, abre espaço para um aspecto crucial da noção de simplicidade: a extrema controvérsia sobre como ela deve ser encarada. Este e outros pontos serão discutidos a seguir.

\subsection{Outras críticas}

Em sua tese de doutorado, Agnaldo Portugal propõe um uso (alternativo ao de Swinburne) do teorema de Bayes e das experiências religiosas para justificar racionalmente o teísmo. Encontram-se condensadas, nesta tese, várias das mais influentes críticas contemporâneas ao princípio da simplicidade. Dentre essas, destacamos as seguintes, por pensarmos serem de especial relevância: 
- $\quad$ O infinito matemático e o infinito teológico. Swinburne pensa que o Deus teísta é uma hipótese muito simples, pois é a postulação de um ser com propriedades infinitas, algo mais simples do que um ser com propriedades finitas. A noção de infinito usada por Swinburne é admitidamente tirada da física e da matemática. Para Jill Le Blanc, no entanto, o conceito teológico de infinito é o do ilimitado, o misterioso, do qual só podemos falar por analogia. Já o conceito de infinito, na matemática, é facilmente apreendido. Assim, Le Blanc defende que o uso da noção matemática de infinito no conceito de Deus impede que se reconheça o Deus do teísmo nele.

As várias facetas do princípio. Mario Bunge tem uma abordagem clássica do tema. Segundo ele, o princípio da simplicidade apresenta as dimensões lógica, semântica, epistemológica e pragmática. Dentro da classificação de Bunge, a noção de simplicidade usada por Swinburne abrange as dimensões lógica (que consiste em discutir termos, proposições e teorias simples), semântica e, fugindo à classificação, ontológica. Bunge pensa que definir quando uma teoria apresenta simplicidade lógica é extremamente difícil, pois cada teoria pode ser formulada de vários modos que variam em complexidade. Além disso, uma teoria simples pode se basear em suposições complexas e vice-versa. Do ponto de vista semântico, a simplicidade é indefinível (por depender do contexto histórico e cultural da teoria analisada) ou desinteressante (pois só poderíamos medir a simplicidade semântica em linguagens formais). Essa abordagem, segundo a opinião de Portugal, mostra que a noção de simplicidade é controversa e, ainda que se admita a noção de Swinburne, deixa aberta a possibilidade de ocorrência de conflito entre duas dimensões da simplicidade, caso este em que não haveria critério para decidir entre uma dimensão ou outra.

Contra a impessoalidade e universalidade do princípio. Alguns filósofos têm argumentado que o princípio da simplicidade, apesar de ter seu papel na escolha de teorias, não é universal, totalmente impessoal, necessário e a priori, como o quer Swinburne. Entre esses filósofos, encontram-se Rom Harré, Mary Hesse e o próprio Agnaldo Portugal. Este pensa que a simplicidade deveria ser vista como um conceito cujo conteúdo e aplicação depende do contexto científico específico do debate, não se caracterizando como um princípio impessoal e universal. Hesse defende que não deveríamos tomar a simplicidade como um princípio universal para escolher uma teoria, pois teorias baseadas e selecionadas meramente em simplicidade são raras na história; e, além disso, cada caso é particular, sendo que a tendência geral será não procurar por teorias mais simples, mas procurar por mais dados e teorias mais compreensivas. Harré, por sua vez, admite o papel heurístico da simplicidade na escolha de teorias, mas diz que ela não é o critério decisivo (nem configura um princípio 
necessário) para essa escolha: este papel caberia ao conhecimento de fundo reconhecido pela comunidade científica. Esse ponto merece destaque.

Swinburne tem um argumento adicional a favor do seu princípio da simplicidade. Segundo ele, o emprego do conhecimento de fundo no juízo sobre teorias pressupõe o uso do critério de simplicidade. Dizer que uma teoria $h$ se encaixa com nosso conhecimento anterior não basta, pois poderíamos ter uma teoria que se encaixasse com esse conhecimento de um modo bastante complexo e estranho. Caso fosse desse modo, poderíamos ter várias teorias que se encaixassem muito bem no nosso conhecimento de fundo e não teríamos como escolher entre elas. Sem um critério como a simplicidade, a seleção de teorias na ciência se tornaria arbitrária e irracional.

Vale registrar novamente que a noção de conhecimento de fundo adotada por Swinburne inclui apenas teorias empíricas que façam parte da área de pesquisa analisada ou dos campos vizinhos e conhecimentos tautológicos. Entretanto, ressalta Portugal, podemos ver a matemática, leis lógicas dedutivas, valores heurísticos e princípios indutivos como parte do conhecimento anterior compartilhado pela comunidade científica. Esse conhecimento não é nem tautológico nem empírico, mas claramente pode ser pensado como parte do corpo de informação que define certa área ou uma atividade teórica como científica. Caso seja desse modo, mesmo o princípio de simplicidade pode ser considerado parte do conhecimento anterior com o qual a comunidade científica analisará teorias rivais. Nesse caso, não é o conhecimento anterior que precisa do princípio da simplicidade para ser aplicado, é o princípio da simplicidade que precisa do conhecimento anterior para ser aplicado em situações conflitantes. Isso traz grandes dificuldades à ideia de que o princípio de simplicidade pode ser aplicado de maneira impessoal. Além disso, a simplicidade pode expressar o modo como uma hipótese se relaciona com o nosso conhecimento anterior, mas não diz nada sobre a natureza do critério de conformidade com esse conhecimento. $\mathrm{O}$ critério de conformidade não pode ser reduzido ao de simplicidade porque não faz parte de sua definição.

\section{Conclusão}

Tendo em vista a discussão realizada até agora, cremos ser possível dar uma resposta à questão inicialmente proposta, isto é, até que ponto Swinburne responde as críticas de Hume e Kant quanto à possibilidade de fundamentação racional da crença em Deus. Vejamos, então, a qualidade de cada resposta. 
Quanto à fraqueza da analogia, parece sensato afirmar que a proposta de Swinburne põe por terra essa crítica, pelo simples fato de que Swinburne não usa uma analogia nas suas versões do argumento teleológico.

Como já foi dito, caso a aplicação do princípio da simplicidade fosse válida, Swinburne teria respondido satisfatoriamente todas as críticas de Hume e Kant. No entanto, parece haver grandes dificuldades no uso do princípio da simplicidade. De fato, é difícil ver como esse princípio pode ser um critério totalmente objetivo, impessoal e universal de escolha entre hipóteses. $\mathrm{O}$ fato de que a noção de simplicidade apresenta diversas dimensões e varia de acordo com o contexto científico mostra que há ao menos algum elemento nessa noção que não é a priori.

Além disso, temos a possibilidade aberta de que o princípio da simplicidade esteja incluído no conhecimento de fundo da comunidade científica que julga hipóteses. Neste caso, é ainda mais problemático sustentar o caráter a priori e impessoal desse princípio.

Por fim, parece superficial a ideia de que a simplicidade é o critério decisivo para a escolha de hipóteses. Como disse Tom Harré, esta parece ser a conformidade com o conhecimento de fundo compartilhado pela comunidade científica. Uma hipótese, ainda que complexa, caso se encaixe ao conhecimento já adquirido pela ciência, será preferível a uma hipótese que, embora muito simples, não é compatível com o conhecimento científico já sedimentado.

Assim, parece haver bons motivos para rejeitar o uso do princípio da simplicidade, ao menos do modo como Swinburne o propõe.

No entanto, caso se rejeite o princípio da simplicidade, a abordagem de Swinburne, que seria totalmente bem-sucedida em responder Hume e Kant, volta a sentir a influência das críticas desses autores, ao menos em alguns pontos.

A questão de saber como se pode determinar a natureza de Deus através de indícios empíricos, usados nos argumentos teístas, é respondida por Swinburne com o princípio da simplicidade. O Deus teísta é a hipótese de explicação pessoal mais simples que pode haver. No entanto, como vimos, parece haver dúvida quanto à simplicidade do teísmo, em particular, quanto à sua simplicidade em confronto com o naturalismo. De fato, se a noção de simplicidade inclui postular o menor número possível de entidades, a não postulação de entidades é mais simples do que a postulação de apenas uma, tornando o naturalismo a hipótese mais simples, e não o teísmo. Isso serve para mostrar que a controvérsia quanto ao modo de se encarar a simplicidade torna problemático apoiar-se com tanto vigor num critério 
como esse ${ }^{6}$.

Parece sensato afirmar, portanto, que, no que concerne à questão da determinação da natureza de Deus, Swinburne dá uma resposta no mínimo controversa e bastante problemática. Isso faz com que, ao analisarmos as críticas, nesse quesito, de Hume, percebamos que a resposta de Swinburne parece não ser satisfatória. Obviamente, a crítica, feita por Kant, de que os argumentos do desígnio e cosmológico não permitem a determinação das propriedades de Deus mantém-se, da mesma forma. No entanto, Kant trata os dois argumentos mencionados como argumentos dedutivos, algo que Swinburne, como vimos, não faz. Para Kant, aqueles argumentos só seriam bem-sucedidos se demonstrassem a necessidade do Ser Supremo. Por esse motivo, o argumento ontológico é a única prova possível da existência de Deus. Swinburne não pensa desse modo. Sua abordagem quer aproximar-se mais da ciência do que da metafísica, preferindo termos como "probabilidade" e "ganho de poder explanatório" do que "necessidade". Quanto à determinação das propriedades de Deus, Kant pensa que ela deve se dar de modo totalmente a priori; Swinburne, no entanto, parte de uma espécie de "mínimo denominador comum" das principais religiões teístas e chega a essas três propriedades: onipotência, onisciência e liberdade perfeita. Daí, diz ele, seguem todas as outras propriedades. O fato de que essas últimas propriedades são dedutíveis das três primeiras torna, a seu ver, o teísmo mais simples. No entanto, temos, mais uma vez, a questão da simplicidade, e o problema ressurge.

Diferentemente, a questão do término adequado da explicação parece ter recebido uma boa resposta. Swinburne defende que devemos continuar buscando explicações enquanto o ganho de poder explanatório não for superado pela perda de simplicidade. Há, como vimos, dúvidas acerca da simplicidade do teísmo e, ainda mais, acerca da própria noção de simplicidade. No entanto, é certo que o ganho de poder explanatório é um quesito muito valorizado na elaboração e escolha de hipóteses, e parece correto afirmar que o ganho de poder explanatório justifica a introdução do Deus teísta na discussão, embora não garanta sua existência. Pode-se argumentar, como Hume e Mackie fizeram, que o próprio Deus teísta não terá explicação, e que, assim, o problema é apenas levado a um nível superior, onde trocamos um elemento inexplicado por outro. No entanto, não é necessário que tenhamos a explicação de uma explicação para que a aceitemos. Caso fosse assim, nunca poderíamos aceitar nenhuma explicação científica e a atividade investigativa da ciência cairia por terra.

6 É possível argumentar que o teísmo, embora menos simples, seja superior em termos de poder explanatório. Essa é, de acordo com o que pensamos, uma tese bastante forte. Mas não é isso que Swinburne argumenta. Ele definitivamente pensa que o teísmo é mais simples do que o naturalismo, como já foi dito. 
Por esses motivos, pensamos que a crítica de Hume quanto ao término da explicação não se sustenta. O ganho de poder explanatório é um bom motivo para, ao menos, considerar a hipótese teísta na discussão.

Assim, concluímos que Swinburne responde a maioria das críticas de Hume e Kant. No entanto, a problemática relacionada ao seu uso do princípio da simplicidade como critério decisivo na escolha de teorias parece justificar a tese de que sua proposta não consegue refutar a crítica de Hume e Kant quanto à determinação das propriedades de Deus.

Convém, após essa conclusão, fazer uma última pergunta: o fato de que Swinburne parece não conseguir responder satisfatoriamente o problema da determinação da natureza de Deus nos argumentos teístas justifica-nos a dar por encerrada (ou por impossível) a discussão acerca da existência de uma divindade? Dificilmente. De fato, mantém-se, à luz da proposta de Swinburne, o problema de identificar, nos indícios empíricos usados nos argumentos teístas, o Deus do teísmo. Mas isso não justifica a conclusão peremptória e impensada de que a questão está além da nossa possibilidade de conhecimento.

Outras possibilidades, além da abordagem de Swinburne, têm surgido na discussão contemporânea acerca da existência de Deus. Apenas a título de informação, mencionamos o trabalho do filósofo americano Alvin Plantinga, que vem defendendo a ousada tese de que a crença na existência de Deus é uma crença básica, para a qual não precisamos apresentar evidências. Para Plantinga, a crença em Deus seria análoga à crença em outras mentes ou no passado (Ver PLANTINGA, 2000). Outro trabalho que merece menção é o de William Alston, que propõe uma justificação da crença teísta com base na noção de "prática doxástica" e nas experiências religiosas dos cristãos (Ver ALSTON, 1991). Alston não segue a linha do racionalismo forte de Swinburne, que quer uma justificação totalmente objetiva e racional. Ele pensa que isso é impossível, do mesmo modo como é impossível a justificação totalmente objetiva e racional das experiências sensórias. A justificação que ele propõe é limitada aos integrantes da prática doxástica cristã, um modo socialmente estabelecido de formar crenças com base em certos fundamentos.

Propostas como essas, com concepções em certos aspectos tão diferentes do que Hume entendia como justificação racional de uma crença, e do que Hume e Kant entendiam como consistindo o campo da experiência possível, mostram com bastante clareza que o campo atual da discussão é amplo demais para que descartemos tão facilmente a possibilidade de conhecimento nessa área.

Pode-se concluir, desse modo, que, assim como nenhuma tese filosófica é livre de críticas, a proposta de Swinburne contém falhas que permitem a aceitação da validade de 
certas críticas de Hume e Kant. No entanto, essas falhas não permitem que se conclua pelo ceticismo radical que esses autores apregoaram. Do mesmo modo como qualquer outra tese filosófica, o teísmo (ou o ateísmo) é uma tese passível de críticas. Ao menos por agora, a questão da existência de Deus ainda não foi decidida. Mas também não foi provada a impossibilidade de chegarmos a uma resposta acerca dela. O que parece ser incentivo suficiente para que continuemos a explorar essa área.

\section{Referências Bibliográficas:}

- ALSTON, William. Perceiving God: The epistemology of Religious Experience. Ithaca and London: Cornell University Press. 1991.

- $\quad$ FAWKES, Don \& SMYTHE, Tom. Simplicity and Theology. Religious Studies 32. 1996. pp. 259-270.

- HUME, David. Diálogos sobre a Religião Natural. Tradução, introdução e notas de Álvaro Nunes. Lisboa/Portugal: Edições 70, 2005.

- $\quad$ KANT, Immanuel. Crítica da Razão Pura. Tradução de Manuela Pinto dos Santos e Alexandre Fradique Morujão. Introdução e notas de Alexandre Fradique Morujão. $5^{\text {a }}$ edição. Coimbra: Fundação Calouste Gulbenkian, 2001.

- $\quad$ MACKIE, John Leslie. The miracle of Theism: arguments for and against the existence of God. New York: Oxford University Press, 1982.

- PlANTINGA, Alvin. Warranted Christian Belief. New York: Oxford University Press. 2000.

- PORTUGAL, Agnaldo Cuoco. Theism, Baye's Theorem and Religious Experience: an Examination of Richard Swinburne's Religious Epistemology. Tese de doutorado. King's College. 2005.

- $\quad$ SWINBURNE, Richard. The existence of God: Second Edition. New York: Oxford University Press, 2004 Mackie, Induction and God. Religious Studies 19.

1983. pp. 385-91. 